\title{
ENTRE ENCONTROS E DESENCONTROS: NARRATIVAS DE CONSTITUIÇÃo DOCENTE EM CIÊNCIAS ${ }^{1}$
}

\author{
BETWEEN MATCHES AND MISMATCHES: NARRATIVES OF THE TEACHING \\ CONSTITUTION IN SCIENCES
}

DOI: $\underline{\text { 10.23926/RPD.2526-2149.2020.v5.n3.p1909-1926.id820 }}$

\author{
Leonardo Priamo \\ Tonello \\ Graduando de Licenciatura \\ em Ciências Biológicas \\ (UFFS) \\ Bolsista do Programa de \\ Educação Tutorial - \\ PETCiências \\ (FNDE/SESu/MEC) \\ leonardo.priamo.tonello@gm \\ ail.com
}

\begin{abstract}
Resumo: O processo de constituição docente perpassa diversas questões, como a formação, o contexto político e social, chegando à dimensão da atuação profissional, formando uma complexa tessitura. O trabalho tem por objetivo apresentar e examinar o processo de constituição docente de um licenciando em Ciências Biológicas durante seu percurso formativo, a partir de escritas narrativas realizadas no Diário de Formação (DF). Foi possível identificar o estabelecimento de quatro momentos emergentes nas escritas reflexivas das narrativas: i) tomada de consciência do ser professor, ii) problematização e reflexão crítica da sala de aula, iii) a busca de sentido para o ensino: os desafios do fazer/ser docente e iv) ressignificação das ações e afirmação do ser professor. Assim, considera-se a importância de investigar e refletir sobre a docência como categoria reflexiva da constante formação docente, que, entre encontros e desencontros, o ser professor se constitui.
\end{abstract}

Palavras-chave: Ensino de Ciências. Identidade Docente. Narrativas. Diário de Formação.

\begin{abstract}
The teaching constitution process goes through several issues, such as education, the political and social context, reaching the dimension of professional performance, forming a complex weave. The objective of this work is to present and examine the teaching constitution process of a graduate student in Biological Sciences during his training path based on narrative writings made in the Training Diary (TD). It was possible to identify the establishment of four emergent moments in the reflective writing of the narratives: i) awareness of being a teacher, ii) problematization and critical reflection in the classroom, iii) the search for a meaningful teaching: the challenges of teaching end being a teacher and iv) reframing of actions and affirmation of being a teacher. Thus, the importance of investigating and reflecting on teaching is considerad as a reflective category, from the constant teacher training, which between matches and mismatches, being a teacher is constituted.
\end{abstract}

Keywords: Science Teaching. Teaching Identity. Narratives. Training Diary.

\footnotetext{
${ }^{1}$ Este texto contou com a orientação do Prof. Dr. Roque Ismael da Costa Güllich, tutor do PETCiências que participou do processo de minha formação no programa, tutorando e dialogando sobre as atividades desenvolvidas no âmbito do grupo e também na relação Universidade-Escola, sobre as quais foram produzidas as experiências e reflexões deste trabalho.
} 


\section{CONSIDERAÇÕES INICIAIS}

O ser, estar e fazer-se docente, é um contínuo caminho profissional entre encontros e desencontros [...] (DF, junho, 2018).

Inicio este trabalho com esta frase, que, de forma geral, suscita a discussão e reflexão sobre a formação de professores. Ela faz pensar os momentos de ser, do estar e do fazer-se docente, podendo ser lida de outra forma, como processo de constituição profissional. Esta constituição perpassa por várias questões, tais como a formação, o contexto político e social, chegando à dimensão da atuação profissional. Neste sentido, a formação de professores não ocorre apenas pela acumulação de saberes e técnicas, mas também "através de um trabalho de reflexividade crítica sobre as práticas e de (re)construção permanente de uma identidade pessoal" (NÓVOA, 1995, p. 25). Assim, acredita-se que as propostas de formação de professores:

[...] devem ir além do ensino que pretende uma mera atualização científica, pedagógica e didática e se transforma na possibilidade de criar espaços de participação, reflexão e formação para que as pessoas aprendam e se adaptem para poder conviver com a mudança e com a incerteza (IMBERNÓN, 2011, p. 19).

É nas interações e nas vivências da prática e ação docente que o sujeito se faz professor, uma vez que nestes contextos ocorre a constituição de um sujeito histórico e cultural, nas relações intersubjetivas com o outro (VIGOTSKI, 2001). O sujeito professor, na perspectiva histórico-cultural, está em constante formação, por isso assume um processo contínuo e permanente da constituição profissional (MIZUKAMI, 2002).

Esta noção de que o contexto, as interações e as experiências contextuais são primordiais à constituição do sujeito, vai ao encontro de Larrosa (2002, p. 25), ao afirmar que: "é experiência aquilo que 'nos passa', ou que nos toca, ou que nos acontece, e ao nos passar nos forma e nos transforma". Assim, viver a docência implica experimentar os processos proporcionados pela própria experiência e, mais do que isso, pela:

possibilidade de que algo nos aconteça ou nos toque, [e isso] requer um gesto de interrupção, um gesto que é quase impossível nos tempos que correm: requer parar para pensar, parar para olhar, parar para escutar, pensar mais devagar, olhar mais devagar, e escutar mais devagar; parar para sentir, sentir mais devagar, demorar-se nos detalhes, suspender a opinião, suspender o juízo, suspender a vontade, suspender o automatismo da ação, cultivar a atenção e a delicadeza, abrir os olhos e os ouvidos, falar sobre o que nos acontece, aprender a lentidão, escutar aos outros, cultivar a arte do encontro, calar muito, ter paciência e dar-se tempo e espaço (LARROSA, 2002, p. 24 [grifo do autor])

Neste sentido, percebe-se a emergência do professor como pesquisador de sua prática, para analisar a experiência da ação docente, na perspectiva da melhoria da qualidade do ensino e também da formação profissional (CARR; KEMMIS, 1988). Em outras palavras, devemos 
considerar um professor para além do trabalho pedagógico e mediador das suas próprias aprendizagens e autoformação (NÓVOA, 1995; 2009; ALARCÃO, 2010), capaz de desenvolver a reflexão sobre o processo docente e o contexto formativo (PORLÁN, 1987; PORLÁN; MARTíN, 2001). Segundo Zabala (2015), necessitamos de um professor com capacidade prática, mas também com capacidade reflexiva; já Alarcão (2010) enfatiza a necessidade do processo de reflexão para formarmos professores reflexivos, na possibilidade de se pensar uma escola como comunidade autorreflexiva.

Desta forma, de acordo com Porlán e Martín (2001), é no processo de escrita de narrativas reflexivas no Diário de Formação (DF), que os professores conseguem descrever, analisar e refletir suas ações para avançar e melhorar/transformar as suas práticas. Como instrumento de reflexão, o DF constribui para o desenvolvimento dos sujeitos envolvidos na insvestigação, conforme estudos de Kierepka, Bremm e Güllich (2019, p. 805): "ao passo que o utilizam, tomam consciência de sua prática, o que implica certa transformação pela via da reflexão, que denominamos intervenção".

Assim, o DF, na literatura, configura-se como mecanismo/instrumento capaz de guiar, catalisar e ser facilitador da reflexão (PORLÁN; MARTÍN, 2001; KIEREPKA, BREMM; GÜLLICH, 2019). Por sua vez, a narrativa é um meio de o investigador conhecer-se a si mesmo e a outros envolvidos no processo (REIS, 2008; TONELLO et al. 2019), indo ao encontro de Ibiapina (2008), ao considerar que a narrativa constitui o sujeito.

Também, segundo Tardif (2012), a experiência pode ser responsável pelo desenvolvimento de saberes docentes, no que compreende os saberes da experiência, próprios do cotidiano e da atividade do professor, ao longo de sua profissão. Assim, acredita-se que as narrativas no DF são um meio para a sistematização e, portanto, a significação desta experiência (LARROSA, 2002), sendo um processo de atribuir sentido às vivências, pois a experiência é a vivência refletida (GÜLLICH, 2013).

Nesta sistematização da experiência, o professor enxerga-se na sua prática, pois "a reflexão sobre a ação, pressupõe um distanciamento da ação. Reconstruímos mentalmente a ação para tentar analisá-la retrospectivamente" (ALARCÃO, 2010, p. 54). Ademais, a narrativa realizada no DF constitui o sujeito, é um ato autêntico de relatar, pensar, rever a própria prática (DATTEIN, 2018). "Então, relatar e rememorar são uma via possível para o entendimento de processos educativos em que emergem indagações, estratégias [...]" (TONELLO et al., 2019, p. 915), potencializando o papel da reflexão na melhora da formação docente, uma vez que "a 
narrativa constitui o sujeito professor, possibilita expressar seu próprio ponto de vista e explicitar teorias implícitas" (PERSON; BREMM; GÜLLICH, 2019, p. 145). Neste sentido,

quanto aos licenciandos, o papel das narrativas na formação é especialmente marcante, pois faz com que o hábito de escrever seja desenvolvido desde o início da formação, bem como a pesquisa sobre a própria prática dá contornos ao perfil do professor a ser formado. Com tempo, o processo tende a fazer com que a escrita se torne parte de sua formação/constituição, assumindo a forma desejada: a pesquisa na ação docente (GÜLLICH, 2013, p. 229).

O modelo que se destaca para potencializar as defesas apresentadas é a InvestigaçãoAção (IA) crítica, a qual integra os processos de reflexão, com objetivo de melhorar a qualidade e transformar o ensino, como processo recorrente do desenvolvimento de espirais autorreflexivas (CONTRERAS, 2002; CARR; KEMMIS, 1988). A IA vem assumindo novas configurações, entre elas, a Investigação-Formação-Ação (IFA), a qual incorpora em seu conceito a reflexão crítica propriamente dita, como categoria formativa, em que os professores passam a refletir, discorrer, avaliar e reconfigurar os contextos investigativos e formativos (ALARCÃO, 2010; GÜLLICH, 2013). Este movimento de reflexão crítica possibilita ressignificar profundamente a relação entre teoria e prática, possibilitando a transformação da realidade, uma unidade de ser e fazer - práxis docente.

Partindo das considerações aqui apresentadas, este trabalho tem por objetivo apresentar e examinar o processo de constituição docente de um licenciando em Ciências Biológicas durante seu percurso formativo, a partir de suas escritas das narrativas realizadas no DF.

\section{Caminho investigativo}

Esta insvestigação é do tipo qualitativa em educação (LÜDKE; ANDRÉ, 2013), baseada num processo de IFA, que se caracteriza pelo diagnóstico de situações práticas, na perspectiva de avaliar, compreender, propor soluções e ações para a melhoria da própria prática (CARR; KEMMIS, 1988; GÜLLICH, 2013). Este processo torna-se fundamental, quando se projeta na possibilidade da percepção de elementos estabelecidos na composição das relações necessárias entre a prática, os sujeitos envolvidos e os contextos particulares de ocorrência. Assim, analisase a constituição docente como parte da experiência e da prática profissional de um licenciando em Ciências Biológicas, em um contexto decorrente de um programa de formação inicial de professores, a saber: PETCiências - Programa de Educação Tutorial (PET- FNDE/SESu/MEC), ligado à Universidade Federal da Fronteira Sul (UFFS), Campus Cerro Largo.

O programa, em sua proposta, aposta como eixo central: "meio ambiente e formação de professores", desenvolvendo atividades baseadas na tríade de ensino, pesquisa e extensão, de 
forma interdisciplinar e articulada, com os grandes temas de Ciência, meio ambiente, do Ensino de Ciências e da formação de professores. Além disso, realiza a inserção de professores em formação inicial em escolas de maneira articulada - licenciandos da Universidade, professores do Ensino Básico e alunos do Ensino Fundamental e Médio.

Durante este percurso, foram possibilitados processos de iniciação à docência e práticas escolares, em escolas públicas do município de Cerro Largo (RS), nos Componentes Curriculares de Ciências (no Ensino Fundamental) e Biologia (no Ensino Médio), em um período de julho de 2017 a novembro de $2019^{2}$. As escritas narrativas eram realizadas sempre após alguma prática pedagógica desenvolvida na escola, geralmente com frequência de uma vez por semana, sobre os momentos mais significativos vivênciados da prática. Neste contexto, como integrante do programa PETCiências, desenvolvi as narrativas no DF, nos moldes que defendem Porlán e Martín (2001). Segundo os autores, DF consiste em um instrumento do trabalho do professor investigador, como importante estratégia formativa, para pensar e repensar as impressões da experiência em sala de aula, sobre os fenômenos que o professor vivencia no seu ser e fazer docente.

Cabe ressaltar que a estrutura e organização do PETCiências pela tríade, como um todo, é ampla e demonstra solidez em seus processos, para o qual também contribui nas narrativas e reflexões apresentadas. Dentre as atividades desenvolvidas, considera-se a possibilidade de socialização coletiva e um conjunto de situações que fortalecem a formação e a construção da identidade profissional: a possibilidade de integrar o ensino, a pesquisa e a extensão, ao encontro de um rompimento com o sectarismo e dualidades, tais como teoria e prática, universidade e escola, formação inicial e continuada, etc.; pesquisa por meio de contextos e problemas reais - como relatos de experiência e pesquisa da própria prática; utilização de redes e mídias sociais como estratégia formativa; ser protagonista e participante em projetos sobre formação de professores e Ensino de Ciências (GÜNZEL, et al., 2020).

Ao recorrer ao diário, como registro da experiência, levo em consideração: "o espaço acadêmico esqueceu a lentidão da leitura, a delicadeza da leitura, essa forma de tratar o texto como uma força que nos leva além de nós mesmos, além do que o texto diz, do que o texto

\footnotetext{
${ }^{2}$ Importante ressaltar que ainda sou bolsista do PETCiências em julho de 2020, época de escritura deste artigo. Considero, que a escrita deste texto, é uma leitura narrada de um recorte temporal, como integrante e bolsista do programa no período de 3 anos (2017-2019), que marca um percurso formativo integrado, desde o início no curso de graduação de Licenciatura em Ciências Biológicas (da UFFS, Campus Cerro Largo) e que se projeta na possibilidade de continuar atuante no programa, até a conclusão do curso de graduação. Assim, este texto, além das contribuições práticas e teóricas para a o campo do conhecimento, carrega um teor importante para e na formação docente em Ciências Biológicas - experienciadas como parte das atividades no PETCiências.
} 
pensa ou do que o texto sabe" (LARROSA, 2003, p.109). Desta forma, à medida que se significam estas ações, a experiência é analisada e conceitualizada, dado o caráter cíclico e desenvolvimentista da IFA (ALARCÃO, 2010).

Nesse sentido, o professor, de um facilitador das aprendizagens, também se projeta para um investigador de suas concepções, ações docentes e a dimensão formativa de forma ampliada (PORLÁN, 1987). Sendo assim,

\begin{abstract}
em nossa experiência, um recurso metodológico nucleador de todo este processo é o Diário. Sua utilização, periódica permite refletir o ponto de vista do autor sobre os processos mais significativos da dinâmica em que ele está imerso. É um guia para reflexão sobre a prática, favorecendo a tomada de consciência do professor sobre seu processo de evolução e seus modelos de referência. Favorece, também, o estabelecimento de conexões significativas entre o conhecimento prático e o conhecimento disciplinar, o que permite uma tomada de decisão mais fundamentada. Através do diário, se pode realizar focalizações sucessivas na problemática que se aborda, sem perder as referências ao contexto. Por fim, propicia também o desenvolvimento de níveis descritivos, analítico-explicativos e avaliativos do processo de investigação e reflexão do professor (PORLÁN; MARTíNS, 2001, pg.23 [tradução própria]).
\end{abstract}

Nesse sentido, além de o DF integrar o corpus de situações vivenciadas anteriormente, permite recorrência das impressões práticas, refletido neste trabalho a partir de recortes que apreendem processos de constituição docente enquanto licenciando, como caminho de reflexão.

Para análise e produção dos resultados sobre o DF, foram demarcados e digitalizados os trechos das narrativas, categorizando-as conforme os indícios e o objetivo do trabalho, possibilitado pela Análise Documental, conforme o subsidio teórico de Lüdke e André (2013), compreendendo três etapas básicas: i) pré-análise: leitura atenta e identificação dos contextos e impressões das práticas ao qual tratavam as narrativas no DF; ii) exploração do material: realiza-se uma leitura mais aprofundada no documento, buscando demarcar e verificar momentos gerais capazes de incorporar e asemelhar características de relação e significado; iii) tratamento dos resultados: realiza-se a interpretação e sistematização das análises, em direção da produção de categorias ou, neste caso, de momentos emergentes deste processo.

Assim, conforme o objetivo de invetigação, os momentos a posteriori no tratamento dos resultados foram ganhando sentido neste processo da análise documental sobre indícios que permitissem um olhar analítico sobre o ser docente e a constituição profissional nas narrativas do DF, dentro da dimensão conceitual de reflexão crítica (ALARCÃO, 2010; LIBERALI, 2008; NÓVOA, 2009; SILVA, 2000; SCHÖN, 2000; ZEICHNER, 2008).

Desta forma, como pesquisador que escrevia e refletia sobre a prática, busco desenvolver um processo de reflexão crítica. Com esta perspectiva na formação de professores, 
ocorre a tomada de consciência do ser e do fazer pedagógico, sobre as relações e ações estabelecidas, sobre o processo de ensino e aprendizagem, o desenvolvimento e constituição profissional. Nesse sentido, o processo de reflexão, incluído e desenvolvido na IFA, "possibilita a constituição docente e a própria ampliação da investigação-ação como modelo de formação" (GÜLLICH, 2013, p. 196).

\section{ENCONTRAR E DESENCONTRAR: DAS EXPERIÊNCIAS À CONSTITUIÇÃO DOCENTE NAS NARRATIVAS DE UM JOVEM PROFESSOR DE CIÊNCIAS BIOLÓGICAS}

Posso considerar o estabelecimento de quatro momentos emergentes no DF, que versam e sintetizam de forma geral a constituição docente nas escritas das narrativas e que dão sentido à discussão própria do ser docente enquanto licenciando. São elas: $i$ ) tomada de consciência do ser professor, ii) problematização e reflexão crítica da sala de aula, iii) a busca de sentido para o ensino: os desafios do fazer/ser docente e iv) Ressignificação das ações e afirmação do ser professor. Enfatizo e trago em destaque, no início de cada momento, alguns excertos ${ }^{3}$ característicos, que dão indícios do que se está sendo abordado, facilitando as discussões.

\subsection{MOMENTO 1: A TOMADA DE CONSCIÊNCIA DO SER PROFESSOR}

Neste dia me senti estimulado, com certeza e vontade de estar ali. Pensei, que em um passado não muito distante, estava na mesma posição, cheio de dúvidas, incertezas, me constituindo aluno, um cidadão e olha só, hoje constituindo-me professor! Em outras palavras, processo formativo... (DF, Julho, 2017).

Em um dia corriqueiro, de uma aula de Ciências, cheguei na sala de aula, e um aluno me pergunta:

-“você será professor?"

Logo, o respondo:

- "Sim serei um futuro professor"!

Este mesmo aluno, me olhou com olhar de espanto, e fala:

-“como alguém pode querer ser professor?...lhe desejo muita sorte!”

A partir deste dia, mudei totalmente minhas concepções sobre minha formação e já não tinha mais volta, a semente da inquietação sobre minha constituição docente estava plantada. Não me desmotivei pela fala do aluno, mas pelo contrário, percebi naquele aluno, não apenas suas desmotivações frente a profissão docente, mas que, acima de tudo, não necessitava sorte e sim, uma sólida formação profissional. Logo me remeti também, de quando assumia o papel de aluno na escola básica, em que apresentava uma percepção semelhante a deste aluno. E neste singelo pensamento, está guardado uma das principais ideias chaves para compreender como se dá o

\footnotetext{
${ }^{3}$ Tomo como opção, a fim de dar destaque, que os excertos que caracterizam cada momento retirados do Diário de Formação (DF), serão colocados em letra de tamanho 10, espaçamento simples, no corpo do texto com recuo de 4 centímetros da margem esquerda, com o mês e ano respectivamente, a exemplo: (DF, Mês, Ano).
} 
desenvolvimento e a constituição docente. Comecei compreender então, que nem sempre quis ser professor - como evidenciado no diálogo com o menino e remetendome em sua posição - que nem sempre, tive motivações para seguir o caminho profissional docente, que nem sempre tive as propriedades de um bom professor. Enfim, não nasci sendo professor, nem muito menos com o que se espera de um (DF, Novembro, 2017).

Posso perceber, desde o momento inicial, o papel da formação inicial a partir do caminho formativo, do diálogo entre professor-aluno e, posteriormente, da reflexão acerca do ocorrido. O momento 1 apresenta e caracteriza-se como a tomada de consciência do ser professor, propriamente dita. Pela pesquisa da própria prática (narrativa reflexiva do diário), sou capaz de tomar consciência da importância da formação docente.

Considero que impressões como estas foram encontradas, principalmente, nos primeiros contatos com a sala de aula e com a constituição docente (ainda em 2017, quando estava iniciando a iniciação à docência). Ao passo que me proponho a compreender as primeiras inquietações e expectativas em relação ao ser professor, fortaleço ainda mais a constituição e identidade profissional. As reflexões deixam de forma explícita um processo, uma transformação que caracteriza o docente, pois, conforme a escrita, não nascemos professor, tornamo-nos professor, assim como não nascemos médicos, tornamo-nos médicos; não nascemos engenheiros, tornamo-nos engenheiros, e assim por diante. Cabe resaltar, ainda, que se continua tornando sempre mais professores, a constituição docente não se esgota com o fim da formação inicial, mas, pelo contrário, é um processo contínuo, conforme ressalta Mizukami (2002).

Normalmente se tem uma percepção intrínseca e engessada na sociedade, de que, sim, o professor apresenta um "dom", como, por exemplo, de trabalhar com pessoas, ter propriedades de oratória, boa relação com o outro, didática em sala de aula, etc. Este aspecto apresenta-se em afirmações na sociedade tais como: "nossa, como você tem paciência para lidar com crianças, nasceu para ser professor!”. O professor, sim, deve gerir pessoas, saber trabalhar em sala de aula, e, acima de tudo, com as adversidades que encontrar em seu ambiente de trabalho; no entanto, afirmações como estas guardam perversidade enorme, deixando nas sombras o complexo caminho formativo, que o qualifica para exercer seu papel e também a se desenvolver um sujeito plural, com capacidades para além, inclusive, do pensamento científico (CARVALHO; GIL-PÉREZ, 2011; NÓVOA, 1995).

Esta tomada de consciência apresenta-se fundamental para que o professor se reconheça no processo de ensino, na escola e, principalmente, em relação a sua profissão (LIBERALI, 2008). É necessária a consciência crítica sobre a constituição docente, sendo fundamental para 
a inquietação e anseios que instigam o profissional a buscar respostas para problemas que encontrar nos mais diversos contextos da prática e da escola, exigindo sólida formação profissional. Afinal, como assumir o trabalho escolar, atuar no processo de ensino e aprendizagem e buscar melhorias de condições da classe dos professores, se não temos clara a tomada de consciência do ser professor? Como vamos desenvolver a constituição profissional, se tampouco temos consciência do "eu" professor? Poder-se-ia genericamente considerar que a não percepção, perante um problema e/ou algo em questão, torna-se uma incógnita obscura, imperceptível e ingenuamente naturalizada.

Assim, percebe-se que a constituição docente depende fundamentalmente de um estado de consciência do ser professor. No momento em que o sujeito se percebe inserido no processo, isso se torna mais fácil. Dificilmente, o professor poderá orientar e trabalhar as aprendizagens de forma investigativa, ou até mesmo melhorar sua prática, pela investigação, se o docente não tiver vivência investigativa (CARVALHO; GIL-PÉREZ, 2011). Portanto, o momento de narrar e escrever pode ser propício, pois o professor percebe-se (REIS, 2008), inclusive significando sua experiência, pelo olhar reflexivo e sistemático das vivências que permeiam os contextos e os espaços da escola (LARROSA, 2002).

Neste sentido, Libardi (2008) estabelece a reflexão crítica sob a perspectiva de pedagogia crítica, proveniente principalmente de Paulo Freire, na qual se enfatiza o processo de tomada de consciência, fundamental para o campo das transformações profissionais e sociais. Para Schön (2000), no estabelecimento do conhecimento prático realizado na reflexãoação-reflexão o professor desenvolve sua profissionalização, ao examinar, interpretar e avaliar suas atividades. Considero fundamental esta tomada de consciência na capacidade de identificação e problematização das ações em ambiente de trabalho (PORLÁN; MARTíNS, 2001), conforme segue no momento 2 .

\subsection{Momento 2: Problematização E REFleX̃̃o CRítica da SAla de AUla}

\footnotetext{
Interessante, como a sala de aula, muito conhecida por nós professores, acaba por ser um elemento onde se passa a maior parte do espaço-tempo que perpassa a experiência entre os professores e alunos. Nela, grande parte das aprendizagens são desenvolvidas, metodologias empregadas, avaliações e impressões de todo este conjunto de processos que se perpassam. Se perguntasse a alunos já concluintes, que parte da escola ele lembra mais, certamente a grande maioria responderia como sendo a sala de aula. Supostamente, porque é o lugar em que passamos a maior parte de nossa vida enquanto estudante e também como professor. Por isso, cabe pensar, como é esta sala de aula?; qual sua organização e será que é a melhor forma?; será ela um ordenamento do processo e se sim qual?; seria ela obrigatoriamente um elemento que caracteriza o trabalho do professor?; poderia o contexto e o meio ser uma sala de aula?...(DF, Junho, 2018).
} 


\begin{abstract}
Era para ser uma noite de quarta-feira, como qualquer outra, no entanto, tinha algo diferente e especial, o primeiro dia na nova escola e na nova turma, a qual iria começar a realizar as práticas. Por si só, este dia estava carregado de dúvidas, incertezas, motivações, ansiedade e acima de tudo, possibilidades. Desta forma, me desloco até a tão esperada sala de aula. Me surpreendo fortemente! A sala 332, a mim atribuída, era na verdade a cela 332 . Isso mesmo! na porta de entrada, estava escrito, cela 332, com uma mescla de tinta e corretivo escolar, característico do material utilizado pelos alunos. Neste exato momento, as dúvidas, incertezas e inquietações, dispararam proporcionalmente ao meu espanto, de forma exponencial. Imediatamente uma série de pensamentos me tomaram por completo. Tento, compreender o por que os alunos daquela turma, pensam a sala de aula como uma cela? o que os leva pensar desta forma? porque a sala, como um ambiente de construções de aprendizagens, se converte em uma cela, lugar de aprisionamento?. Estes e outros questionamentos, se tornam em um movimento de pensar a docência (DF, Setembro, 2019).
\end{abstract}

Este excerto, apartado e em análise, permite-me perceber que, naquele momento, a escrita caracteriza-se pela problematização da sala de aula na construção das aprendizagens. A problematização, neste caso, baseia-se no questionamento, de por que ser ou não ser. Entre este problema encontrado, pode-se levantar, inclusive, a forma como o ensino é realizado na escola. Esta dicotomia entre cela ou sala (?), me permite remeter a Rubem Alves (2004), sobre as escolas que são "asas" e as escolas que são "gaiolas". Segundo o autor,

Escolas que são gaiolas existem para que os pássaros desaprendam a arte do voo. Pássaros engaiolados são pássaros sob controle. Engaiolados, seu dono pode levá-las para onde quiser. Pássaros engaiolados sempre têm um dono. Deixaram de ser pássaros. Porque a essência dos pássaros é o voo. Escolas que são asas não amam pássaros engaiolados. O que elas amam são os pássaros em voo. Existem para dar aos pássaros coragem para voar. Ensinar o voo, isso elas não podem fazer, porque o voo já nasce dentro dos pássaros. $\mathrm{O}$ voo não pode ser ensinado. Só pode ser encorajado (ALVES, 2004, p. 4).

É o problema prático, que move o professor para o processo de reflexão. Indagar, segundo Marcelo (1992), é um tipo de reflexão que está diretamente ligado com a mudança do professor, visto que possibilita, por meio da análise da prática, realizar-se o estabelecimento de estratégias, ao encontro da mudança da própria prática. Considero que a IFA está diretamente relacionada a este processo, uma vez que a rememoração desenvolvida nas narrativas possibilita recursividade, na qual o professor investigador depara-se com a situação-problema, criando a possibilidade de pensar soluções e teorias que possam servir de base para tal (ALARCÃO, 2010; GÜLLICH, 2013).

O professor, no momento de conflito com seu ambiente de trabalho, a sala de aula, assim como a tentativa de solucionar ou pensar em estratégias que sejam viáveis ou não, desenvolve pensamento prático-reflexivo, conforme enfatiza Zabala (2015). Várias hipóteses estarão pairando pela imaginação do professor, isso pode indicar ampliação do que é estático, para além do fenômeno em si. Poder-se-ia pensar várias possibilidades sobre por que os alunos consideram a sala de aula como uma cela, tais porque talvez o ensino desenvolvido não os 
interessa e motiva, porque o contexto da escola não é favorável à boa convivência em coletividade, os colegas não possuem uma boa relação. Enfim, o professor projeta-se para além do simples pensamento, do que se configura uma cela - concepção dos alunos, a qual apresenta quatro paredes, capaz de isolar do meio externo - mas do entendimento de ser percebida desta forma.

Organizar e ter uma boa leitura dos ambientes de trabalho significa organizar a própria profissão docente, uma vez que o contexto escolar constitui parte da identidade docente. Segundo Imbernón (2011), a escola pode se configurar um nicho ecológico, para o desenvolvimento inclusive da formação docente, no qual deve assumir o papel de sujeito e não do objeto. Problematizar o ambiente de trabalho significa, também, romper com o condicionamento de um mundo perfeito, que não nos causa inquietação e estado de consciência para propor intervenção sobre o determinado fenômeno. Estar dormente, está fortemente arraigado em um sistema aconchegante, em que o mecanismo humano e também cognitivo de despertar, talvez seja dolorida, e de fato, inquietante sair da inércia e do aprisionamento. $\mathrm{O}$ professor experiente na escola é uma etapa de “[...] consolidação do conhecimento profissional educativo mediante a prática apoia-se na análise, na reflexão e na intervenção sobre situações de ensino e aprendizagem concretas e, é claro, em um contexto educativo determinado e específico" (IMBERNÓN, 2011, p. 70). Sendo assim, considero a sala de aula e o contexto escola, como ambiente complexo de interações e aprendizagens, bem como espaço-tempo de formação de novos professores, especialmente pela iniciação à docência que promovem (BRASIL, 2006; TONELLO; WYZYKOWSK; GÜLLICH, 2018;.,TONELLO; SANTOS; OLIVEIRA, 2019; TONELLO, et al., 2019).

\subsection{MOMENTO 3: A bUSCA DE SENTIDO PARA O ENSINO: OS DESAFIOS DO FAZER/SER DOCENTE}

Enfim, entro na sala de aula. Como de praxe, cumprimento a turma, exponho os conteúdos que serão trabalhados, em questão naquele dia, o sistema excretor, logo após, faço a chamada nominal. Ao final, no fundo da sala, mão se ergue, entusiasmado um aluno pergunta:

-Professor, agora já posso ir embora?

Percebo o tom irônico do questionamento. Esta pergunta, só vinha a confirmar, a ideia de que a sala de aula, se configurava uma cela, um lugar, de insatisfação em estar, em obrigação, em penalidade ou castigo. Talvez, para este aluno e possivelmente para os demais, outros locais, como a casa fossem mais interessantes. Neste momento, percebi meu desafio como professor naquela turma. Mais do que ensinar os conteúdos de Biologia, deverei desenvolver o sentido destes conteúdos para estes alunos. Acredito, ser necessário desenvolver um ensino mais voltado a realidade destes alunos (DF, Outubro, 2019). 
Percebo, neste ensaio de reflexão, que a ação docente configura-se no fazer e, consequentemente, no ser docente. A constituição, neste sentido, acontece no trabalho e nas interações com os alunos em sala de aula. Segundo Vigotski (2001), o sujeito se estabelece e constitui nas interações com o outro. $\mathrm{O}$ autor assinala a importância das relações em sala de aula, entre professor-aluno e aluno-aluno, pois no encontro de pares, nas interações assimétricas e por meio da linguagem mediada, ocorre a aprendizagem. Nesta perspectiva, o professor é fundamental como mediador das aprendizagens, por meio de um ensino intencional, que deve ser capaz de proporcionar a possibilidade de elevar a zona de desenvolvimento proximal para o nível potencial dos estudantes (VIGOTSKI, 2001).

Conforme o momento 3 , a constituição docente acontece na tentativa da melhora da prática pedagógica. Ela decorre de uma interação estabelecida entre o caráter das aprendizagens com a própria aprendizagem. Enquanto professor em formação, coloco-me no processo, na tentativa de melhorar a prática pedagógica, no instante em que consigo identificar um ensino que desenvolva o sentido para os alunos das aprendizagens, ao encontro das motivações. Suposições para isso, inclusive, são levantadas como um ensino mais contextualizado. Portanto, a contextualização dos conteúdos em sala de aula, como forma de desenvolver o sentido do ensino. Ao encontro disso, "o professor é o intermediador do processo educativo escolar e tem um papel primordial na construção de práticas pedagógicas, que oportunizem a aprendizagem de conhecimentos científicos escolares, a formação humana dos sujeitos e o tratamento contextualizado [...]" (TONELLO; WYZYKOWSK; GÜLLICH, 2018, p.380), possibilitando maior estado de consciência e significação das aprendizagens.

Nesse sentido, o professor assume o desafio de estabelecer as possibilidades para as aprendizagens, em outras palavras, saber dirigir o processo pedagógico dos alunos. Desenvolver o interesse pelo ensino é fundamental para que ele de fato ocorra; talvez um dos principais pontos seja reconhecer que "nenhum aluno é uma folha de papel em branco em que são depositados conhecimentos sistematizados durante sua escolarização" (DELIZOICOV; ANGOTTI; PERNAMBUCO, 2011, p. 131).

Enfatizo que o fazer do professor, no campo de suas ações, precisa ter um devir permanente de reflexão e significando estas experiências, tomado aqui como campo profícuo do estabelecimento do ser e do constituir-se professor. O momento em que o docente dá importância ou pensa no modo de ensino estabelecido, ele também atribui esta função a sua própria formação. Considerar o ensino e suas diferentes formas de trabalho, é considerar o ser professor. Pelo fazer, atribui-se e percebe-se o ser, da mesma forma que o ser se constitui pelo 
fazer. Neste sentido, a reflexão se constitui como central. Evidencia-se a importância no processo reflexivo, pois, nas palavras de Alarcão (2010, p. 53): “a aprendizagem é um processo transformador da experiência no decorrer do qual se dá a construção do saber”, e, portanto, é pela via da formação, dos processos reflexivos e da experiência docente e o conjunto desses processos, que o professor busca a constituição e o seu desenvolvimento profissional.

\title{
3.4. MOMENTO 4: RESSIGNIFICAÇÃ̃ DAS AÇÕES E AFIRMAÇÃO DO SER PROFESSOR
}

\begin{abstract}
Quando me permito pensar no processo de ensino e aprendizagem, como um andar de bicicleta por exemplo, penso que da mesma forma, é algo lento e a autonomia é central. A criança começa a desenvolver suas habilidades no processo do andar de bicicleta, quando se desafia na possibilidade de cair, mas também na possibilidade de aprender. A cada dia que me coloco como professor na sala de aula, penso o que posso melhorar como profissional. O que eu tenho a contribuir na melhoria da prática pedagógica, para que seja mais relevante para os estudantes. Penso que ser professor é isso, estar sempre buscando trabalhar com os alunos, entre os alunos e para os alunos. A medida que isso se passa, e paro para pensar o que estou fazendo, me sinto mais professor e isso é incrível! (DF, Novembro, 2019).
\end{abstract}

Apoiado nas evidências da escrita, percebo o processo da autônomia e um movimento de transformação, levando em conta a ressignificação das ações e a afirmação do ser professor (identidade docente). Este momento apresenta-se de forma transversal sobre os outros; no entanto, proponho uma discussão individualizada, levando em conta o importante papel que exerce sobre os processos e possibilidades formativas. $\mathrm{O}$ professor que pensa na sua prática pedagógica está colocando-a em perspectiva, em movimento, em (futura) intervenção. Remeto a Güllich (2013), para quem o processo de reflexão perpassa pela necessidade de uma conceitualização, de um diálogo construtivo e mediativo. Ainda segundo o autor, é neste momento que a IFA torna-se efetiva na perspectiva da transformação sobre as concepções, as ações, o currículo e do contexto escolar. Neste sentido, a observação pode permitir a avaliação e a mobilização para novos planejamentos e ressignificações da prática, pensando em uma melhoria da própria escola como um todo, relacionando-se com a IA (CARR; KEMMIS, 1988).

Também percebo que é durante as sistematizações das experiências que o professor se permite enxergar na sua prática, no qual Larrosa (2002) fala na significação da experiência, pelo ato de parar e pensá-la. Também é neste momento que se cria certo espelhamento, gerando importante diálogo da prática e do ser docente, ao encontro de alcançar a (re)significação, caracterizando um diálogo formativo (GÜLLICH, 2013).

Assim, considero que, quando se defende o desenvolvimento da autonomia, integra-se a esta discussão um ponto indivisível, que é a ideia de qual concepção tem o professor do ser docente e de sua ação. Pensar em autonomia é projetar a superação de uma necessidade, que 
permeia, tanto em um estado básico como mais complexo, do professor que busca ressignificar sua formação e constituição docente, por meio da reflexão crítica. Isso permite provocar inquietação no profissional em sempre estar se aperfeiçoando, buscando melhor aprender para melhor ensinar e melhor ensinar, para melhor aprender.

Considero que o processo de intervenção sobre a prática ou mobilização a ela, é um estágio avançado da reflexão. Pensar o sujeito como transformante da própria realidade, ou protagonista de suas transformações, considera uma formação sólida e suficientemente no desenvolvimento dos conhecimentos. Penso aqui um ser autônomo, no campo das transformações em um processo contínuo, constante, atuante sobre sua forma de ver e pensar o mundo - portanto, uma autonomia em estado superior de atividade (GÜLLICH, 2013; CARR; KEMMIS, 1988).

O ser professor é também pensar nas transformações possíveis. Tudo ocorre em relações, com relações e entre as relações. O processo de relação é fundamental na transformação, porque se entende que também ocorre pelo caminho das percepções e constituição docente.

Neste ponto, o processo de formação de professores no contexto educacional, por meio das narrativas, apresenta-se como regulador e determinante das representações que se apresentam sobre o olhar do individual ao coletivo e vice-versa (PORLÁN; MARTÍN, 2001). Neste caso, posso inferir que, quando o professor compreende o seu entorno e estabelece suas dinâmicas investigativas no dia a dia da sala de aula, é também o mais autêntico ser e constituição profissional.

\section{CONSIDERAÇÕES FINAIS: UM EXERCÍCIO METARREFLEXIVO DE MINHAS APRENDIZAGENS}

Considero, por meio deste trabalho, baseado nos aportes no DF enquanto licenciando, a relação sobre os aspectos da formação docente e uma importante discussão acerca das narrativas da experiência vivida. Por meio deste processo, houve quatro momentos, que versaram e resumiram a constituição docente nas escritas das narrativas. A primeira delas, a $i$ ) tomada de consciência do ser professor, apresentou-se como o estado de consciência frente à própria profissão docente e sua ação. Percebo o professor como central, como agente incluído nos processos, levando em consideração sua formação e necessidade reflexiva, contrapondo uma ideia de que o professor nasce pronto e acabado, mas que o professor torna-se professor. A ii) problematização e reflexão crítica da sala de aula, como seu próprio enunciado, considera a problematização da sala de aula como ambiente amplo, sujeito a diversas situações, que 
apresentam e destacam o contexto escolar, como ambiente complexo de interações e aprendizagens. Por sua vez, a iii) a busca de sentido para o ensino: os desafios do fazer/ser docente, por meio da tentativa de compreender e desenvolver o sentido do ensino, que o professor baseia o seu fazer docente, que, ao se estabelecer, perpassa o ser docente e vice-versa. $\mathrm{O}$ quarto e último, iv) ressignificação das ações e afirmação do ser professor, evidencio um processo autônomo e transformante sobre a ressignificação das ações e, juntamente com esse processo, a afirmação do ser e da identidade docente.

Enfatizo que os momentos foram marcados por características próprias, ao longo do trabalho, encontram-se indissociáveis na ação e ser docente. Isso pode ser atribuído e caracterizado como um processo contínuo e complexo de reflexão, que perpassa várias dimensões, entre os ambientes da escola os sujeitos envolvidos, a profissão e o ser docente, dimensionando uma identidade, que não é única e acabada. Assim, entendo que professor investigador de sua formação e de sua prática, mostra-se como um importante exercício que deve ser contínuo, sobre os momentos que se traduzem no viver a profissão, que necessitam ser significados e dialogados, na tentativa de compreensão e de um profissional comprometido com a qualidade do ensino e ao mesmo tempo formação de pessoas.

Considero, ainda, que, conforme as narrativas no DF e as reflexões cotruidas neste trabalho, posso com propriedade ressaltar a importância do programa PETCiências e sua inserção de licenciandos nas escolas de atuação, assim como o desenvolvimento da indissociação entre ensino, pesquisa e extensão, no fortalecimento do professor investigador. Desta forma, os mometos tecidos indiciam e apontam para uma contribuição de um pensar diferente sobre o ser professor, o que possibilitou identificar e refletir acerca das nuances sobre a constituição profissional. Por isso, a importância de investigar e refletir sobre a docência, do ponto de vista da IFA, como categoria de reflexão crítica, construtiva e formativa da constante formação docente, que, entre encontros e desencontros, o ser professor se constitui.

\section{REFERÊNCIAS}

ALARCÃO, Isabel. Professores reflexivos em uma escola reflexiva. 7. ed. São Paulo: Cortez, 2010.

ALVES, Rubem. Asas ou Gaiolas. A Arte do Voo ou a busca da Alegria de Aprender. Porto: Asa Editores, 2004.

BRASIL. Secretaria de Educação Fundamental. Programa de Educação Tutorial- PET: Manual de orientações Básicas. Brasília: SEB, 2006. 
CARVALHO, Anna Maria Pessoa de; GIL-PÉREZ, Daniel. Formação de professores de ciências: tendências e inovações. 10ª ed. São Paulo: Cortez, 2011.

CARR, Wilfred; KEMMIS, Stephen. Teoria crítica de la enseñanza: investigación-acción en la formación del profesorado. Barcelona: Martinez Roca, 1988.

CONTRERAS, José. Autonomia de professores. Tradução de Sandra Trabucco Valenzuela; revisão técnica, apresentação e notas à edição brasileira de Selma Garrido Pimenta. São Paulo: Cortez, 2002.

DATTEIN, Raquel Weyh. A mediação de escritas reflexivas compartilhadas na formação em ciências no contexto de um processo de iniciação à docência. Dissertação (Mestrado), Programa de Pós-Graduação em Educação nas Ciências, Universidade Regional do Noroeste do Estado do Rio Grande do Sul, Ijuí, 2018. Disponivel em: http://bibliodigital.unijui.edu.br:8080/xmlui/handle/123456789/5038. Acesso em: 29 mar. 2020.

DELIZOICOV, Demétrio; ANGOTTI, José André.; PERNAMBUCO, Marta Maria. Ensino de Ciências: Fundamentos e Métodos. 4. ed. São Paulo: Cortez, 2011.

GÜNZEL, Rafaela Engers; TONELLO, Leonardo Priamo; MARSANGO, Daniel; GÜLLICH, Roque Ismael da Costa. Desafios e interrelações entre Ciêncis, Ambiente e Formação de Profesores: o PETCiências e a extensão universitária. Vivências, v. 16, n. 31, p. 195-208, 29 jun. 2020. Disponivel em: http://revistas.uri.br/index.php/vivencias/article/view/197. Acesso em: 08 jul. 2020.

GÜLLICH, Roque Ismael da Costa. Investigação-Formação-Ação em Ciências: um caminho para reconstruir a relação entre livro didático, o professor e o ensino. Curitiba: Editora Prismas, 2013.

IMBERNÓN, Francisco. Formação docente e profissional: formar-se para a mudança e a incerteza. São Paulo: Cortez, 2011.

IBIAPINA, Ivana Maria Lopes de Melo. Pesquisa colaborativa: investigação, formação e produção de conhecimentos. Brasília: Líber Livro, 2008.

KIEREPKA, Janice Silvana Novakowski; BREMM, Daniele; GÜLLICH, Roque Ismael da Costa. O processo investigativo-reflexivo como propulsor da constituição docente. Revista Prática Docente. v.4, n.2, p.791-809, jul/dez, 2019. Disponível em:

http://periodicos.cfs.ifmt.edu.br/periodicos/index.php/rpd/article/view/480/240. Acesso em: 29 mar. 2020.

LÜDKE, Menga.; ANDRÉ, Marli Eliza Dalmazo Afonso de. Pesquisa em educação: abordagens qualitativas. 2. Ed. São Paulo: EPU, 2013.

LARROSA, Jorge. Bondía. Notas sobre a experiência e o saber de experiência. Revista Brasileira de Educação, São Paulo, n. 19, jan/fev/mar/abr. 2002. Disponivel em: https://www.scielo.br/pdf/rbedu/n19/n19a02.pdf. Acesso em: 08 jul. 2020. 
LARROSA, Jorge. O ensaio e a escrita acadêmica. Educação \& realidade, v. 28, n. 2, p. 101-115, 2003. Disponivel em:

https://seer.ufrgs.br/educacaoerealidade/article/viewFile/25643/14981. Acesso em: 08 jul. 2020.

LIBERALI, Fernanda Coelho. Formação crítica de educadores: questões fundamentais. Taubaté, SP: Cabral Editora e Livraria Universitária, 2008.

MIZUKAMI, Aria da G. N. et al. Escola e aprendizagem da docência: processos de investigação e formação. São Carlos: EDUFSCar, 2002.

MARCELO, Carlos. García. A formação de professores: novas perspectivas baseadas na investigação sobre o pensamento do professor. 1992. In: NÓVOA, António. Os professores e a sua formação. (2. ed.) Portugal: Ed. Porto, 1992.

NÓVOA, António. Professores: imagens do futuro presente. Lisboa: EDUCA, 2009.

NÓVOA, António. Formação de professores e profissão docente. In: NÓVOA, António. (Org.). Os professores e a sua formação. Lisboa, Dom Quixote, 1995.

PERSON, Vanessa Aina; BREMM, Daniele; GÜLLICH, Roque Ismael da Costa. A Formação Continuada de Professores de Ciências: Elementos Constitutivos do Processo.

Revista Brasileira de Extensão Universitária, v. 10, n. 3, p. 141-147, 2019. Disponivel em: https://periodicos.uffs.edu.br/index.php/RBEU/article/view/10840. Acesso em: 29 mar. 2020.

PORLÁN, Rafael; MARTÍN, José. El diario del profesor: un recurso para investigación en el aula. Sevilla, Díada, 2001.

PORLÁN, Rafael. El maestro como investigador en el aula. Investigar para conocer, conocer para enseñar. Revista Investigación en la escuela, n. 1, p. 63-69, 1987. Disponivel em: https://idus.us.es/bitstream/handle/11441/59047/El\%20maestro\%20como\%20investigador\%2 0en\%20el\%20aula.pdf?sequence=1\&isAllowed=y. Acesso em: 08 jul. 2020.

REIS, Pedro Rocha. As narrativas na formação de professores e na investigação em educação. Nuances: estudos sobre educação, v. 15 n. 16, Presidente Prudente, p.17-34, jan./dez. 2008. Disponível em: https://revista.fct.unesp.br/index.php/Nuances/article/view/174. Acesso em: 08 jul. 2020.

SCHÖN, Donald. Educando o profissional reflexivo: um novo design para o ensino e aprendizagem. Tradução de Roberto Cataldo Costa. Porto Alegre: Artmed, 2000.

SILVA, Ana Maria Costa e. A formação continua de professores: uma reflexão sobre a prática e as práticas de reflexão em formação. Educação \& Sociedade, Campinas, v. 21, n 72, p. 89109, ago. 2000. Disponível em: https://www.scielo.br/scielo.php?pid=S010173302000000300006\&script=sci_abstract\&tlng=pt. Acesso em: 08 jul. 2020.

TONELLO, Leonardo Priamo; WYZYKOWSK, Tamini; GÜLLICH, Roque Ismael da Costa. $\mathrm{O}$ uso de charges e histórias em quadrinhos para potencializar a educação ambiental no ensino de ciências. Ambiente \& Educação: Revista de Educação Ambiental (23) 2, 369-381, 2018. 
Disponivel em: https://periodicos.furg.br/ambeduc/article/viewFile/8446/5491. Acesso: 16 de nov. de 2019.

TONELLO, Leonardo Priamo; CZEKALSKI, Riceli Gomes.; MACHADO, Renata Caroline Dias; GÜLLICH, Roque Ismael da Costa. O papel da reflexão na formação inicial de professores de ciências. Bio-grafía: Escritos sobre la Biología y su Enseñanza, p. 906-915, 2019. Disponivel em: https://revistas.pedagogica.edu.co/index.php/biografia/article/view/10989/7783. Acesso: 29 de mar. de 2020.

TONELLO, Leonardo Priamo; SANTOS, Eliane Gonçalves dos; OLIVEIRA, Mateus dos Santos. Educação Ambiental e Saúde: concientização, autonomia e transformação na prática docente. Bio-grafía: Escritos sobre la Biología y su Enseñanza, p. 982-992, 2019. Disponível em: https://revistas.pedagogica.edu.co/index.php/bio-grafia/article/view/10998/7789. Acesso: 08 jul. 2020.

TARDIF, Maurice. Saberes docentes e formação profissional. Petrópolis: Vozes, 2010.

VIGOTSKI, Lev Semyonovich. A construção do pensamento e da linguagem. São Paulo: Martin Fontes, 2001.

ZABALA, Antoni. A prática educativa: como ensinar. Penso Editora, 2015.

ZEICHNER, Kenneth. Uma análise crítica sobre a "reflexão" como conceito estruturante na formação docente. Educação \& Sociedade, Campinas, v. 29, n. 103, p. 535-554, ago. 2008. Disponível em: https://www.scielo.br/pdf/es/v29n103/12.pdf. Acesso: 08 jul. 2020.

Recebido em: 9 de julho de 2020.

Aprovado em: 20 de outubro de 2020. 